\title{
The Formation of 6,19-Epoxy-3,5-cyclo-steroid
}

$\mathrm{C}_{19}$-Oxygenated steroids are of great use as intermediates for the preparation of the biologically important $\mathrm{C}_{19}$-norsteroids. Now we wish to report the cleavage reaction of 6,19-epoxy-3,5-cyclo-steroid obtained from $6 \beta$-hydroxy-3,5-cyclo-steroid by the application of the transannular reaction using lead tetraacetate. ${ }^{1)}$

The treatment of $6 \beta$-hydroxy-3,5-cyclo- $5 \alpha$-androstan-17-one (I $)^{2)}$ with lead tetraacetate in benzene solution and chromatographic separation of the product furnished, in addition to the unchanged starting $6 \beta$-ol (I), ca. $25 \%$ yield of $6 \beta, 19$-epoxy-3,5-cyclo$5 \alpha$-androstan-17-one (II), m.p. $137 \sim 138^{\circ},[\alpha]_{\mathrm{D}}+150.1^{\circ}$.*1 As expected from the structural analogy with $6 \beta$-alkoxy-3,5-cyclo-5 $\alpha$-steroids, (II) was smoothly solvolyzed in acidic media to give $6 \beta, 19$ - or $3 \beta, 19$-dioxygenated compounds in good yields, depending upon the reaction conditions.

Thus, standing a solution of (II) in aq. acetone containing small amounts of sulfuric acid at room temperature gave 6 $\beta, 19$-dihydroxy-3,5-cyclo- $5 \alpha$-androstan-17-one (III), m.p. 175 $175.5^{\circ},[\alpha]_{\mathrm{D}}+147.3^{\circ}$, on the other hand refluxing the solution yielded the known $3 \beta, 19$ dihydroxyandrost-5-en-17-one (IVa), ${ }^{3)}$ m.p. 207 210,$[\alpha]_{\mathrm{D}}+8.8^{\circ}$, which also could be derived from (III) in aq. acetone sulfuric acid mixture on heating. The treatment of (II) in methanol-sulfuric acid at room temperature afforded a mixture of the methyl ether of (III), m.p. $104 \sim 105^{\circ},[\alpha]_{\mathrm{D}}+145.2^{\circ}$, and of (IVa), m.p. $145^{\circ},[\alpha]_{\mathrm{D}}+8.6^{\circ}$, at $\mathrm{C}_{6}-$ and $\mathrm{C}_{3^{-}}$ positions, respectively; the latter exclusively being obtainable on refluxing the reaction mixture.

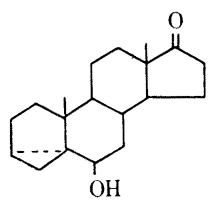

( I )

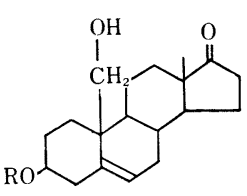

(IVa) : $\mathrm{R}=\mathrm{H}$

(IVb) : $\mathrm{R}=\mathrm{CH}_{3} \mathrm{CO}$

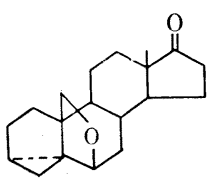

(II)

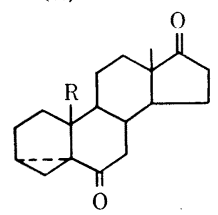

(Va) $: \mathrm{R}=\mathrm{CHO}$

$(\mathrm{Vb}): \mathrm{R}=\mathrm{COOH}$

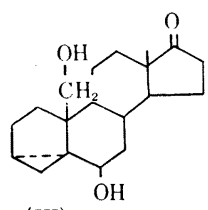

(III)

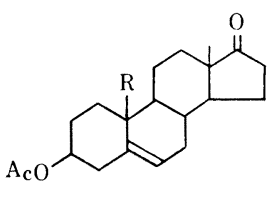

(VIa) $: \mathrm{R}=\mathrm{CHO}$

(VIb) : $\mathrm{R}=\mathrm{COOH}$

When heated a solution of (II) in acetic acid with a small amount of conc. sulfuric acid, there was obtained $3 \beta, 19$-diacetate of (IVa), m.p. $107 \sim 108^{\circ},[\alpha]_{\mathrm{D}}-40.7^{\circ} .3 \beta, 19-$ Diformate of (IVa), m.p. $131 \sim 133^{\circ}$, was formed on similar treatment of (II) in a mixture of $98 \%$ formic acid and conc. sulfuric acid. A solution of (II) in acetic acid in the

*1 Rotations were measured in $\mathrm{CHCl}_{3}$ solution at $578 \mathrm{~m} \mu$ with Zeiss' Photoelectric Precision Polarimeter.

1) G. Cainelli, M. Lj. Mihailovic, D. Arigoni, O. Jeger : Helv. Chem. Acta, 42, 1124 (1959); A. Bowers, L. C. Ibanez, M.E. Cabezas, H. J. Ringold : Chem. \& Ind. (London), 1299 (1960); J. Org. Chem., 27, 1862 (1962). $\quad \mathrm{C}_{\mathrm{H}}$. Meystre, K. Hensler, J. Kalvoda, T. Wieland, C. Anner, A. Wettstein : Experientia, 17, 475 (1961).

2) A. Butenandt, L. A. Suranyi : Ber., 75, 591 (1942).

3) J.S. Mihina : U.S.P. 2, 856, 415, Oct. 14 (1958); C. A. 53, 6298 (1959). 
presence of dil. sulfuric acid or $\mathrm{BF}_{3}$-etherate afforded a monoacetate (IVb), m.p. 160 $161^{\circ},[\alpha]_{\mathrm{D}}+3.9^{\circ}$, on standing at room temperature.

Oxidation of (III) in acetone solution with ca. two equiv. moles of Jones's reagent) (the same reagent was used for all oxidation processes in this work) gave $10 \beta$-formyl3,5-cyclo-5 $\alpha$-estrane-6,17-dione (Va), m.p. $224 \sim 225^{\circ},[\alpha]_{\mathrm{D}}+108.5^{\circ}$; with the excess oxidizing agent both (III) and ( Va) were converted into the corresponding $10 \beta$-carboxylic acid $(\mathrm{Vb})$, m.p. $260 \sim 262^{\circ},[\alpha]_{\mathrm{p}}+118.7^{\circ}$. Direct oxidation of (II) regulating the amount of the oxidation agent in a similar manner gave the compound $(\mathrm{Va})$ or $(\mathrm{Vb})$ in high yield.

The monoacetate (IVb) was smoothly oxidized into the corresponding $10 \beta$-formyl derivative (VIa), m.p. $148 \sim 150^{\circ},[\alpha]_{\mathrm{D}}-228.3^{\circ}$, but resisted to further oxidation even with the excess oxidizing agent to give a low yield of the $10 \beta$-carboxylic acid (VIb), m.p. $253^{\circ}$ (decomp.), $[\alpha]_{\mathrm{D}}-79.3^{\circ}$.

New substances encountered in this work mentioned above were characterized by ultraviolet, infrared, and nuclear magnetic resonance spectra confirmatory of the structures presented, and satisfactory analytical data were obtained for all compounds. The authors are currently undertaking studies on the preparation of $\mathrm{C}_{19}$-norsteroids starting from the substances prepared here and the results will be reported shortly.

\section{Takamine Laboratory \\ Sankyo Co., Ltd. \\ 1-888, Nishi-shinagawa, \\ Shinagawa-ku, Tokyo.}

July 13, 1962

$\begin{array}{ll}\text { Katsumi Tanabe } & \text { (田辺克巳) } \\ \text { Rinji Takasaki } & \text { (高崎林治) } \\ \text { Kiyoshi Sakai } & \text { (酒井 浄) } \\ \text { Ryōzō Hayashi } & \text { (林了予) } \\ \text { Yasuhiro Morisawa } & \text { (森沢靖弘) }\end{array}$

4) K. Bowden, I. M. Heilbron, E. R. H. Jones, B.C.L. Weedon : J. Chem. Soc., 1946, 39.

\section{Mutagenic Activity of 4-Hydroxyaminoquinoline 1-Oxide}

4-Nitroquinoline 1-oxide (4NQO) and its related compounds are calling attention due to the powerful mutagenic action. ${ }^{1 \sim 3)}$ Although, up to date, some postulations have been presented to explain this activity, the mechanism has not been established unequivocally. In the present communication it is indicated that 4-hydroxyaminoquinoline 1 -xide (4HAQO), one of the microbial reduction products of $4 \mathrm{NQO}^{4)}$ has mutagenic activity on Aspergillus niger.

The spore suspension of $A$. niger strain W. prepared by the similar manner as previously reported ${ }^{1)}$ was treated with various concentrations of $4 \mathrm{HAQO} \cdot \mathrm{HCl}$ at $28^{\circ}$ for 24 hours. The aliquots of the suspension were plated on agar medium composed of $5 \%$ glucose, $0.5 \%$ peptone, $0.2 \%$ yeast, extract and $0.1 \% \mathrm{~K}_{2} \mathrm{HPO}_{4}$, and incubated for 72 hours at $28^{\circ}$. The appeared colonies were picked up at random on agar slants

1) T. Okabayashi : Hakkôkôgakuzasshi, 33, 513 (1955).

2) S. Mashima, Y. Ikeda : Appl. Microbiol., 6, 45 (1958).

3) H. Endô, A. Wada, K. Miura, Z. Hidaka, C. Hiruki : Nature, 190, 833 (1961).

4) T. Okabayashi, A. Yoshimoto : More detailed data will de shown in a subsequent paper. 